\title{
Mesotheliomas with small cell features: report of eight cases
}

\author{
Nelson G Ordóñez \\ Department of Pathology, The University of Texas MD Anderson Cancer Center, Houston, TX, USA
}

\begin{abstract}
Mesotheliomas with small cell morphology are rare and only one study of such cases has been published. As a result of their rare occurrence, some investigators have cast doubt on the existence of such a histologic variant of mesothelioma. This investigator reports a series of eight cases of epithelioid mesothelioma with small cell features, all of which originated in the pleura. Seven of the patients were men and one was a woman. Four patients had a history of asbestos exposure. Histologically, four of the mesotheliomas were epithelioid and four biphasic. The proportion of small cells seen in these cases constituted 80 to $100 \%$ of the tumor included in the biopsy material and 15 to $20 \%$ of the tumor present in the pneumonectomy specimens. Immunoreactivity for calretinin, keratin 5/6, keratin 7, pan-keratin, WT1, podoplanin, and mesothelin was seen in all cases tested for these markers. All of the cases were negative for MOC-31, Ber-EP4, CEA, CD15, TAG-72, TTF-1, chromogranin A, synaptophysin, CD99, and desmin. The mean survival of the six patients for whom this information was available was $\mathbf{8 . 2}$ months. It is important for pathologists to be aware that mesotheliomas can present small cell features and, because of this, they can be confused with other malignancies that can exhibit similar morphology. The value of immunohistochemistry in the differential diagnosis of these tumors is discussed. Modern Pathology (2012) 25, 689-698; doi:10.1038/modpathol.2011.202; published online 6 January 2012
\end{abstract}

Keywords: histopathology; immunohistochemistry; mesothelioma; small cell

Mesotheliomas can exhibit a wide variety of histologic patterns and, based on their histologic features, they have been classified into three main types: epithelioid, sarcomatoid, and mixed epithelioid and sarcomatoid (biphasic), the most common of these being the epithelioid. Most epithelioid mesotheliomas exhibit a tubulopapillary, adenomatoid (microglandular), or solid pattern, but on occasion, may present other histologic patterns, including deciduoid, ${ }^{1-3}$ clear cell, ${ }^{4,5}$ signet-ring, ${ }^{6}$ adenoid cystic, ${ }^{7}$ rhabdoid, ${ }^{8}$ pleomorphic, ${ }^{9,10}$ oncocytoid, ${ }^{11}$ glomeruloid, ${ }^{12}$ and small cell. ${ }^{13}$ Some of the variants of epithelioid mesothelioma, such as the small cell variant, have not yet been well-defined and their existence remains somewhat controversial. ${ }^{14,15}$

In 1992, Mayall and Gibbs ${ }^{13}$ were the first to draw attention to a variant of mesothelioma that could potentially be confused with small cell carcinoma of the lung and which they termed small cell mesothelioma. As their study was based on 13 cases that they identified from post-mortem tissue from 160 cases of

Correspondence: Dr NG Ordóñez, MD, Department of Pathology, The University of Texas MD Anderson Cancer Center, 1515 Holcombe Boulevard, Houston, TX 77030, USA.

E-mail: nordonez@mdanderson.org

Received 1 October 2011; revised 20 October 2011; accepted 23

October 2011; published online 6 January 2012 mesothelioma, some investigators have suggested that the morphologic features Mayall and Gibbs described may have been caused, at least in part, by post-mortem artifact. ${ }^{15}$ Additionally, Krismann et $a 1^{14}$ have raised doubts regarding the existence of small cell mesotheliomas because the German Mesothelioma Registry, which contains over 6000 mesothelioma cases, did not have a single example of such a case. It should be mentioned that, although small cell mesotheliomas were mentioned in the 2004 WHO Classification as a histologic variant of epithelioid mesothelioma, their histologic features were not defined nor were any illustrations provided. ${ }^{16}$ Although this variant has been mentioned sporadically over the years, to my knowledge, the 1992 Mayall and Gibbs ${ }^{13}$ report represents the only published study that focused on small cell mesotheliomas. The purpose of this article is to report eight cases of epithelioid mesothelioma with small cell features and to better define the diagnostic criteria for this type of lesion, as well as to attempt to resolve some of the controversies that exist in regards to this rare mesothelioma variant.

\section{Materials and methods}

Eight cases of mesothelioma with small cell features were identified from a review of 960 cases of meso- 
Table 1 Antibodies used in this study

\begin{tabular}{|c|c|c|c|c|}
\hline Marker & Source & Type & Dilution & Antigen retrieval \\
\hline Calretinin & Zymed (South San Francisco, CA, USA) & PAb (rabbit) & $1: 20$ & Yes (citrate) \\
\hline Pan-keratin & Dako (Carpinteria, CA, USA) & AE1/AE3 MAbs & $1: 50$ & Yes (citrate) \\
\hline Keratin 7 & Dako & OV-TL 12/30 & $1: 100$ & Yes (enzymatic digestion) \\
\hline Keratin $5 / 6$ & Dako & $\mathrm{D} 5 / 16 \mathrm{~B} 4 \mathrm{MAb}$ & $1: 100$ & Yes (citrate) \\
\hline WT1 & Dako & $6 \mathrm{~F}-\mathrm{H} 2 \mathrm{MAb}$ & $1: 40$ & Yes (Tris-EDTA) \\
\hline Podoplanin & Signet Laboratories (Dedham, MA, USA) & $\mathrm{D} 2-40 \mathrm{MAb}$ & $1: 25$ & Yes (Tris-EDTA) \\
\hline Thrombomodulin & Dako & $1005 \mathrm{MAb}$ & $1: 50$ & Yes (citrate) \\
\hline Mesothelin & Novocastra (Newcastle-upon-Tyne, UK) & $5 B 2$ & $1: 30$ & Yes (Tris-EDTA) \\
\hline MOC-31 & Dako & MAb & $1: 50$ & Yes (citrate) \\
\hline Ber-EP4 & Dako & $\mathrm{MAb}$ & $1: 30$ & Yes (enzymatic digestion) \\
\hline CEA & Lab Vision (Fremont, CA, USA) & PAb (rabbit) & $1: 200$ & No \\
\hline CD15 & Becton-Dickinson (Mountainview, CA, USA) & Leu-M1 MAb & $1: 40$ & Yes (Tris-EDTA) \\
\hline TAG-72 & BioGenex (San Ramon, CA, USA) & B72.3 MAb & $1: 300$ & No \\
\hline TTF-1 & Dako & 8G7G3/1 MAb & $1: 25$ & Yes (citrate) \\
\hline Chromogranin A & Novocastra & LK2H10 MAb & $1: 4000$ & Yes (citrate) \\
\hline Synaptophysin & BioGenex & SNP88 MAb & $1: 75$ & Yes (citrate) \\
\hline CD99 & Dako & $12 \mathrm{E} 7 \mathrm{MAb}$ & $1: 50$ & Yes (Tris-EDTA) \\
\hline Desmin & Dako & D33 MAb & $1: 200$ & Yes (citrate) \\
\hline
\end{tabular}

thelioma from the files of the Department of Pathology at the University of Texas MD Anderson Cancer Center. Several of the cases were referred to this institution for further evaluation and treatment and one was sent to the investigator in consultation. Hematoxylin-and-eosin stained sections were available in all cases. Periodic acid Schiff (PAS) stain with and without diastase digestion was done in selected cases. Immunohistochemical studies were performed on formalin-fixed, paraffin-embedded tissue sections using the avidinbiotin-peroxidase complex method in a Dako AutoStainer (Carpinteria, CA, USA). The primary antibodies are listed in Table 1. The immunostaining was carried out using the LSAB2 peroxidase kit (Dako). To enhance the immunostaining, a heat epitope retrieval procedure was performed using a Black-and-Decker vegetable steamer (Shelton, CT, USA). Briefly, deparaffinized sections were placed in a thermoresistant container filled with a buffer solution. Depending upon the antibody, the buffer solution used was citrate buffer $(\mathrm{pH}$ 6.0) or a 1:1 solution of Tris-EDTA buffer ( $\mathrm{pH}$ 8.0). The antigenantibody immunoreaction was visualized using either 3-amino-9-ethylcarbazole or 3,3'-diaminobenzadine as chromogen. To evaluate the specificity of the immunoreaction, known positive and negative tissues were used as controls. The immunostaining was graded on a sliding scale of $1+$ to $4+$ according to the percentage of reactive cells (trace, $<1 \% ; 1+, 1-25 \% ; 2+, 26-$ $50 \% ; 3+, 51-75 \% ; 4+,>75 \%)$. Electron microscopy studies were performed in three of the cases. Samples of the specimen were fixed in $2 \%$ buffered glutaraldehyde, post-fixed in $1 \%$ osmium tetroxide and embedded in Epon epoxy resin. Ultrathin sections were stained with uranyl acetate and lead citrate.

\section{Results}

\section{Clinical Findings}

Seven patients were men and one was a woman, ranging in age from 52 to 74 years (mean, 64.8).
There was a history of asbestos exposure in four patients and smoking in three. In all of the cases, the mesothelioma originated in the pleura. Two patients received chemotherapy alone; four underwent extrapleural pneumonectomy with two of these also receiving radiotherapy after surgery and one chemotherapy before surgery. Treatment information was not available in the remaining two patients. All six patients for whom follow-up information was available died of disease 3 to 17 months after diagnosis (mean, 8.2 months).

\section{Pathology Findings}

Gross examination of the four pneumonectomy specimens showed diffuse involvement of the visceral and parietal pleura with encasement of the lung. One of the cases had involvement of the diaphragm and pericardium (case 5) and another of the diaphragm alone (case 2). In two of the cases (cases 2 and 5), several of the peribronchial lymph nodes were involved by metastasis and in another (case 4), one of three internal mammary lymph nodes removed at surgery were also involved by metastatic disease. The most significant light microscopic findings are summarized in Table 2. Histologically, four of the tumors were epithelioid and four biphasic. The proportion of the small cell component in these tumors ranged from 80 to $100 \%$ in the biopsy material (cases 1, 6, 7, and 8) and from 15 to $20 \%$ in the pneumonectomy specimens (cases 2, 3, 4 , and 5). In all of the cases, the small cells appeared to be growing in solid nests of closely packed cells often exhibiting a well-defined cell membrane and high nuclear cytoplasmic ratio (Figures 1-3). In two cases, there also were areas in which the cells were arranged in a trabecular (Figures 2a and c) or papillary (Figure 3c) array. The cytoplasm was often eosinophilic and, in four of the cases (cases 1, 2, 5, and 8), the tumor contained focal areas in which the 
cells had clear cytoplasm that, by PAS stain, were shown to contain large amounts of glycogen. The nuclei were round to oval and the chromatin did not appear to be clumped. A small nucleolus could be seen in some of the cells (Figure 3d). In two cases (cases 2, and 4), some of the cells contained intracytoplasmic vacuoles, which appeared to coalesce to form large cystic structures, some of which contained variable amounts of bluish amorphous material that most probably represented proteoglycans (Figures 1e and f). Mitotic activity was generally low $(<5$ mitoses per 10 high-power fields), with the exception of one case (case 1) in which about 20 mitotic figures per $10 \mathrm{HPFs}$ were seen. In some areas, the stroma appeared myxoid (Figures $2 \mathrm{~d}$ and $3 \mathrm{a}$ ); whereas, in others, it was dense and collagenous (Figure $3 \mathrm{~b}$ ). In the pneumonectomy specimens, in addition to the small cell component, a combination of various proportions of other histologic subtypes of epithelioid mesothelioma were also present, including solid, adenoid cystic, and clear cell (case 2); solid and trabecular (case 3); solid, pleomorphic and deciduoid (case 4); and solid and pleomorphic (case 5).

\section{Immunohistochemistry}

Immunohistochemical results are summarized in Table 3. The small cells in all cases strongly reacted for calretinin and the staining was nuclear and cytoplasmic. They also strongly reacted for pankeratin and keratin 7 in all of the cases stained for these markers. All of the cases investigated for keratin 5/6, WT1, podoplanin, and mesothelin expression were positive for these markers, but the staining was variable. None of the cases stained for MOC-31, BerEP4, CEA, CD15, TAG-72, TTF-1, chromogranin A, synaptophysin, CD99, or desmin were positive for any of these markers. Representative immunoreactions for some of the markers investigated in one of the cases are shown in Figure 4.

\section{Electron Microscopy}

In the three cases for which tissue was submitted for ultrastructural evaluation (cases 2, 3, and 4), only the non-small cell component of the tumor was included. The neoplastic cells in these cases appeared to be joined by well-developed junctions. The cell cytoplasm was abundant and contained short profiles of endoplasmic reticulum, a moderate number of mitochondria, and bundles of intermediate filaments, and the cell membrane appeared to be covered by abundant, long, slender microvilli.

\section{Discussion}

Tumors derived from the serosal membranes characteristically display a wide variation in their 

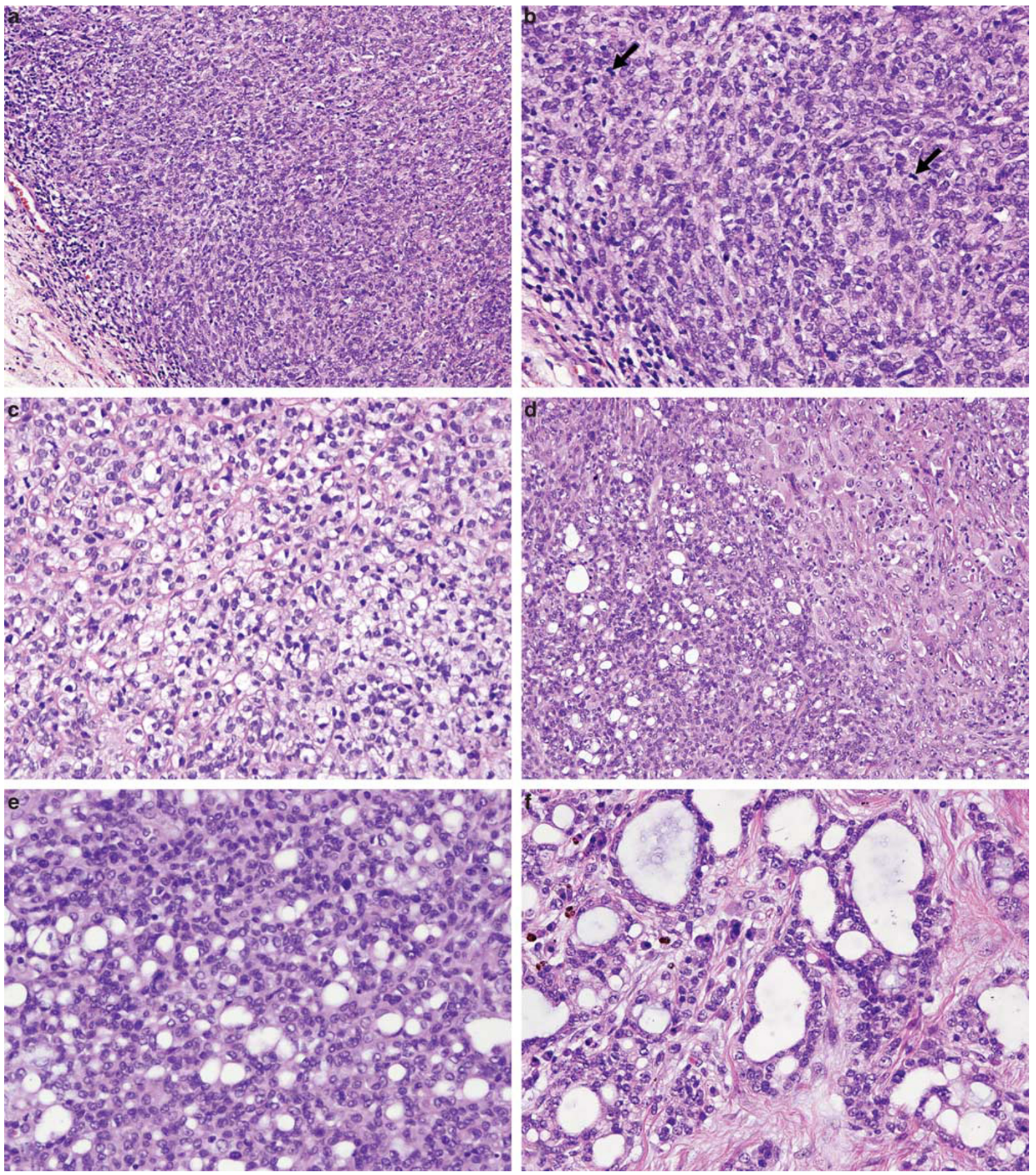

Figure 1 Case 1: (a) Diffuse proliferation of small tumor cells. A few lymphocytes have been included (left lower corner) for size comparison. (b) Higher magnification showing the general appearance of the neoplastic cells. Two mitotic figures are seen (arrows). A few lymphocytes are present in the left lower corner. (c) Another area of the same case showing small tumor cells with well-defined cell membranes and clear cytoplasm which, by PAS stain, proved to contain large amounts of glycogen. Case 4: (d) An area of the tumor composed of small cells (left) and large cells with abundant cytoplasm and deciduoid features (right). (e) Higher magnification of the small cell area showing numerous vacuoles, some of which appeared to coalesce to form larger vacuoles. (f) Clusters of small cells associated with large cystic structures containing variable amounts of proteoglycans. A few inflammatory cells, which are present on the left, have been included for size comparison.

histologic appearance. Mesotheliomas have been classified histologically into three major variants: epithelioid, sarcomatoid, and mixed or biphasic.
The term small cell mesothelioma was first used by Mayall and Gibbs to describe a variant of epithelioid mesothelioma characterized by a monotonous 

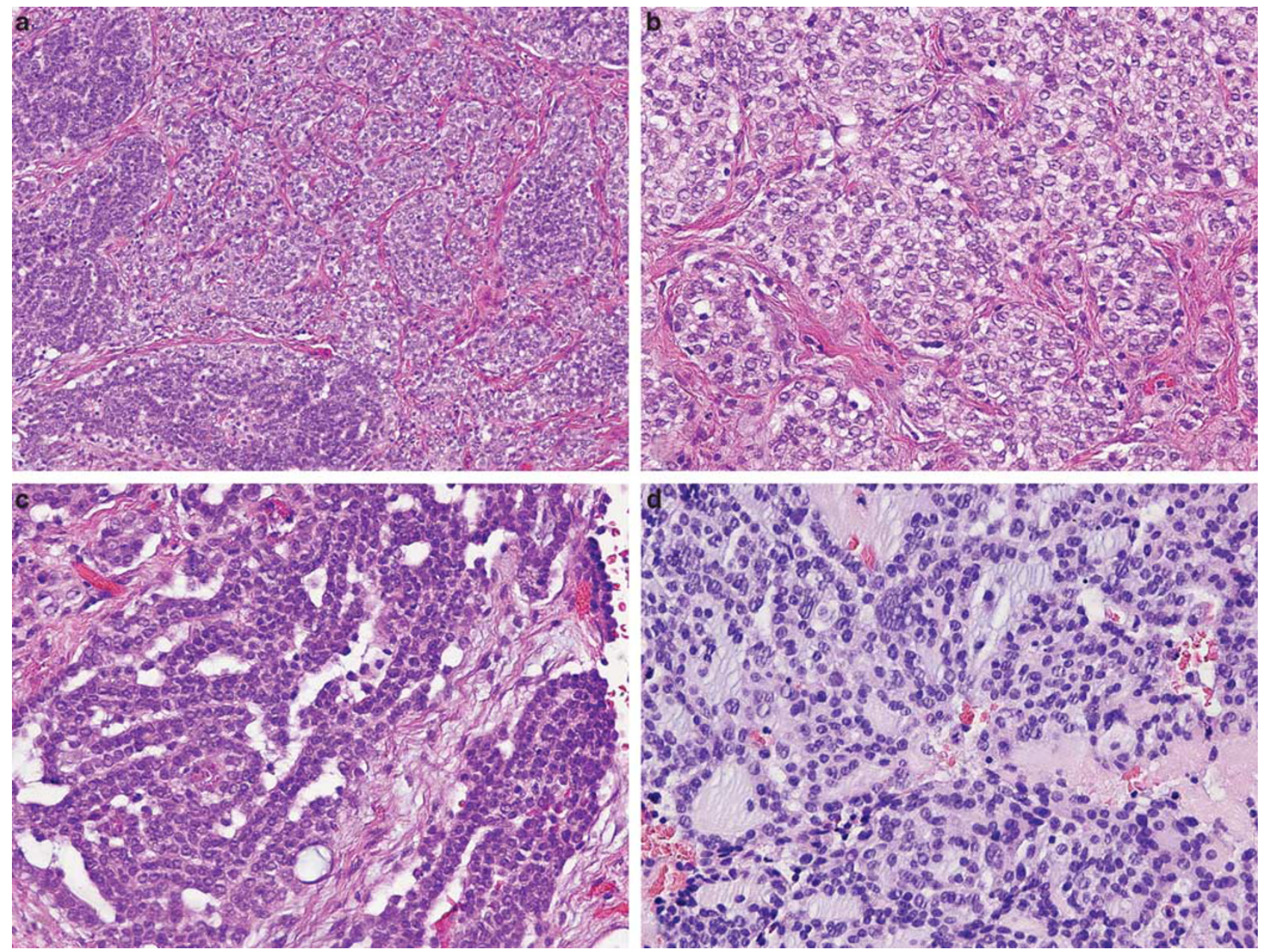

Figure 2 Case 8: (a) The tumor is composed of solid nests of small cells with clear cytoplasm (right) and small cells with eosinophilic cytoplasm arranged in a trabecular array (left). (b) Higher magnification of the clear cell area showing in more detail cellular characteristics of the neoplastic cells. (c) Higher magnification of the cells with eosinophilic cytoplasm exhibiting a high nuclear cytoplasmic ratio. (d) Another area of the same tumor showing the tumor cells embedded in myxoid stroma.

arrangement of uniform small cells that they identified in $13(8 \%)$ of 160 mesotheliomas studied post mortem. ${ }^{13}$ That only $8(0.8 \%)$ of the 960 mesotheliomas cases reviewed for this study represented small cell mesotheliomas indicates that this variant is more rare than was initially thought and this is the most likely reason why its existence has been questioned by some investigators. ${ }^{14}$ Additionally, given that small cell mesotheliomas often occur in association with other subtypes of mesothelioma, it is possible that, during histologic evaluation, this component could be easily overlooked when it is limited to a small percentage of the tumor in a large specimen that has several other histologic mesothelioma variants present that are dominant.

The results in the present investigation show that, in general, the neoplastic cells in small cell mesothelioma maintain the immunophenotype seen in the non-small cell epithelioid areas of the tumor. In all of the cases, the small cells retained the strong positivity for pan-keratin, keratin 7 , and calretinin that was also seen in the areas of the tumors exhibiting a more conventional morphology. Other markers, especially mesothelin and podoplanin, were also demonstrated, but their expression was weaker and occurred in a smaller percentage of cells when compared with that seen in the non-small cell areas of the tumor. In the more differentiated conventional epithelioid mesothelioma areas, both of these markers were usually strongly expressed along the apical surfaces of the neoplastic cells and the reaction often correlated with the presence of long, slender microvilli seen by electron microscopy in this type of tumor; ${ }^{17,18}$ whereas, in small cell mesotheliomas, the staining was often cytoplasmic and, when it occurred in the cell membranes, it was usually weak, a finding which indicates that small cell mesotheliomas should be considered a poorly differentiated variant of epithelioid mesothelioma. Unfortunately, in this study, the small cell component of the tumors was not included in those cases for which material for electron microscopy was submitted; however, some investigators have indicated that small cell mesotheliomas lack the 

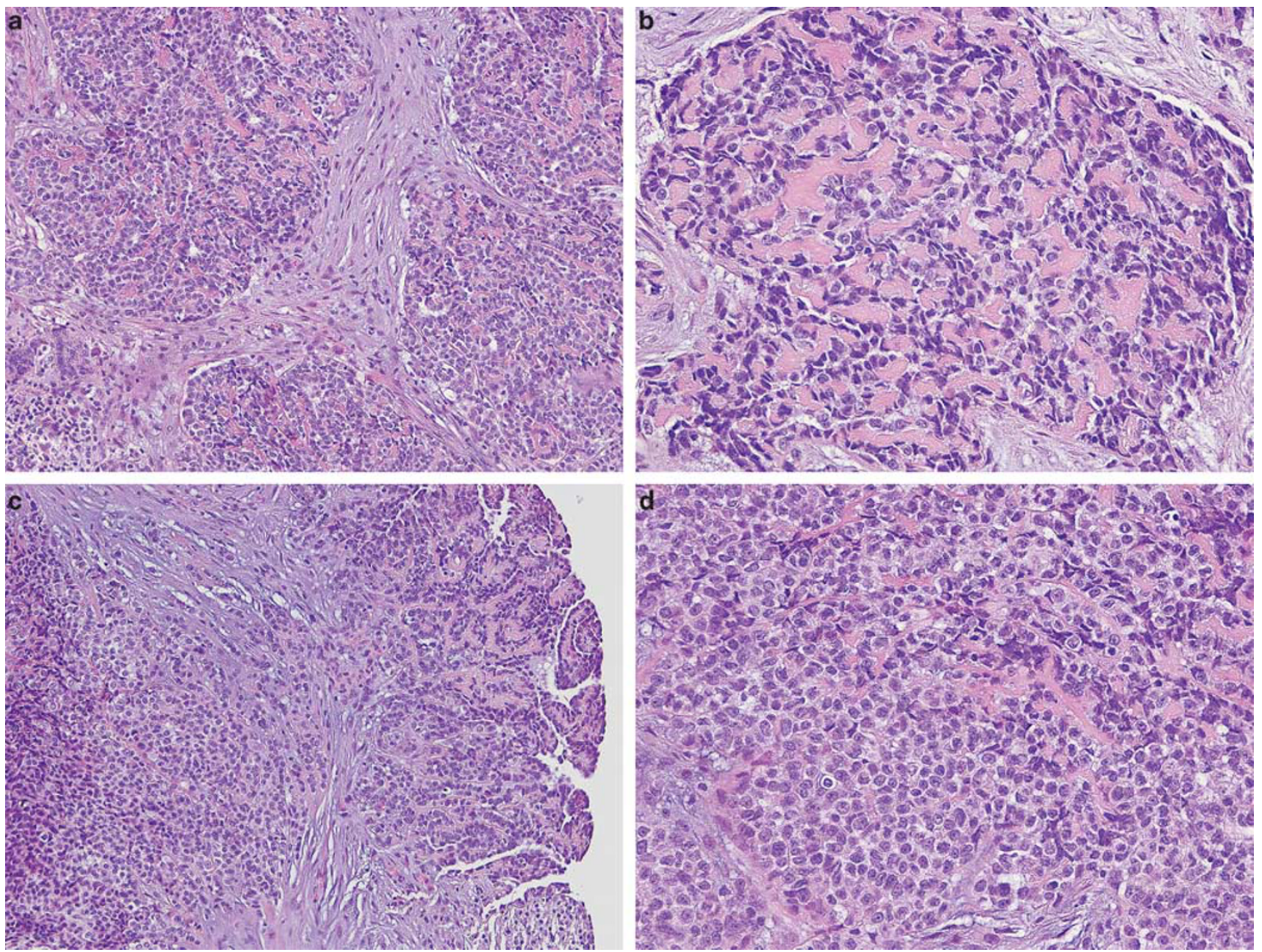

Figure 3 Case 7: (a) Clusters of small neoplastic cells separated by myxoid stroma. (b) Higher magnification of one of these clusters showing groups of neoplastic cells separated by thick bands of dense collagenous stroma. (c) Another area of the same tumor composed of solid clusters of small neoplastic cells, which also appear to be arranged along dense stroma forming small papillary structures (right). (d) Higher magnification of the neoplastic cells in the solid area to better show the cell morphology.

Table 3 Immunohistochemical results

\begin{tabular}{|c|c|c|c|c|c|c|c|c|}
\hline & Case 1 & Case 2 & Case 3 & Case 4 & Case 5 & Case 6 & Case 7 & Case 8 \\
\hline Calretinin & $3+$ & $4+$ & $4+$ & $4+$ & $3+$ & $4+$ & $4+$ & $4+$ \\
\hline Pan-keratin & $4+$ & $4+$ & $4+$ & ND & $4+$ & $4+$ & ND & ND \\
\hline Keratin 7 & $4+$ & $4+$ & ND & $4+$ & $4+$ & $4+$ & ND & $4+$ \\
\hline Keratin 5/6 & $1+$ & $3+$ & $3+$ & $2+$ & $3+$ & $2+$ & ND & $3+$ \\
\hline WT1 & $2+$ & $3+$ & $2+$ & $3+$ & $2+$ & $2+$ & $4+$ & ND \\
\hline Podoplanin & $1+$ & $2+$ & $2+$ & $1+$ & $2+$ & $2+$ & ND & ND \\
\hline Thrombomodulin & ND & ND & ND & $1+$ & ND & ND & ND & ND \\
\hline Mesothelin & $2+$ & ND & $2+$ & $2+$ & ND & ND & ND & ND \\
\hline MOC-31 & 0 & 0 & 0 & 0 & 0 & 0 & 0 & 0 \\
\hline Ber-EP4 & ND & 0 & ND & ND & ND & 0 & ND & 0 \\
\hline CEA & 0 & 0 & 0 & 0 & 0 & 0 & 0 & ND \\
\hline CD15 & 0 & 0 & ND & ND & 0 & 0 & ND & 0 \\
\hline TAG-72 & ND & 0 & 0 & 0 & 0 & 0 & 0 & 0 \\
\hline TTF-1 & 0 & 0 & ND & 0 & 0 & 0 & 0 & 0 \\
\hline Chromogranin A & 0 & 0 & 0 & 0 & 0 & 0 & ND & ND \\
\hline Synaptophysin & 0 & 0 & 0 & 0 & 0 & 0 & 0 & ND \\
\hline CD99 & 0 & 0 & 0 & 0 & 0 & 0 & ND & ND \\
\hline Desmin & ND & 0 & 0 & 0 & 0 & 0 & ND & ND \\
\hline
\end{tabular}

Abbreviations: CEA, carcinoembryonic antigen; ND, not done; TTF-1, thyroid transcription factor-1. 

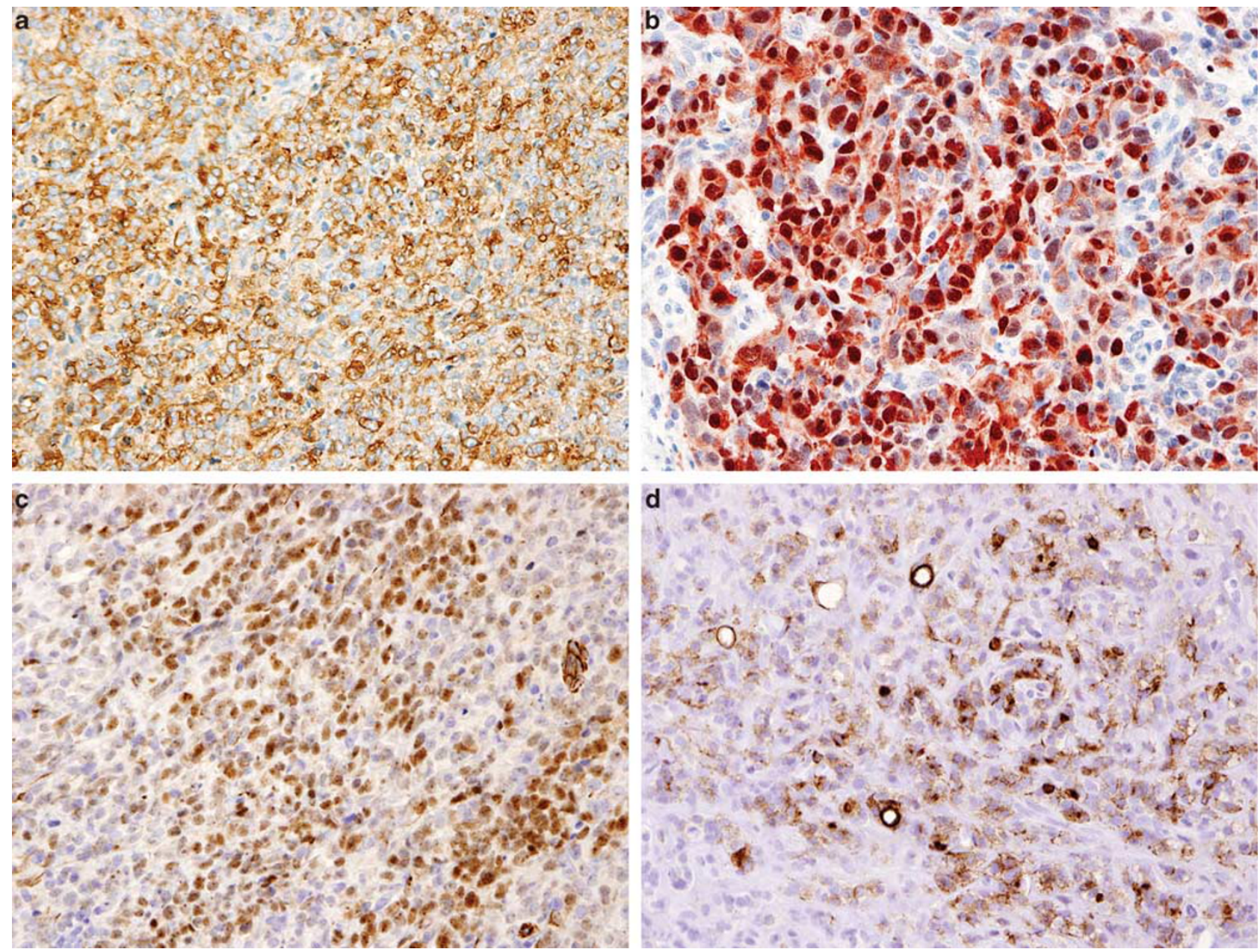

Figure 4 Case 1: (a) Immunohistochemical preparation showing diffuse cytoplasmic positivity for keratin 5/6. (b) Same case showing nuclear and cytoplasmic reactivity for calretinin. (c) Nuclear positivity for WT1. (d) Immunostaining for mesothelin showing area of positivity in the cell membrane and cytoplasm. It also demonstrates the presence of a few intracytoplasmic lumens.

long slender microvilli typically seen in mesotheliomas. ${ }^{13}$

As mesotheliomas can exhibit small cell features, they can be confused with a variety of tumors with similar morphology that can involve the serosal membranes. The four tumors with the greatest potential of being confused with mesotheliomas with small cell features are small cell lung carcinoma, Ewing's sarcoma/peripheral neuroectodermal tumor (PNET), desmoplastic small round cell tumor (DSRCT), and the small cell variant of poorly differentiated synovial sarcoma.

Small cell lung carcinomas, although they occur more frequently in the center of the lung, may also originate in the periphery and, on occasion, may present a diffuse involvement of the entire pleura with little lung parenchymal involvement, thus mimicking a mesothelioma. ${ }^{19-21}$ In addition, cases of a collision tumor formed by a mesothelioma and a small cell lung carcinoma, although exceedingly rare, have also been documented..$^{22}$ Microscopically, the cytoplasmic features of small cell mesothelioma differ subtly from those of small cell lung carcinoma in that, although both types of tumors exhibit a high nuclear cytoplasmic ratio, the amount of cytoplasm in the mesotheliomas with small cell features is greater. In small cell lung carcinomas, cell borders are rarely seen and the nuclei often present a 'saltand-pepper' chromatin and nuclear molding, and lack nucleoli, while in small cell mesotheliomas, the nuclei are more vesicular with finely granular and dispersed chromatin, they more often contain small, but well-defined, nucleoli, and exhibit no nuclear molding. The presence of apoptotic bodies and a very high mitotic activity are both characteristic of small cell lung carcinomas; whereas, small cell mesotheliomas usually lack apoptotic bodies and mitotic activity is much lower. Also, it is not a surprising finding that clear cells resulting from the accumulation of large amounts of glycogen are seen in some areas in the mesotheliomas exhibiting small cell features because mesothelial cells usually contain glycogen ${ }^{23}$ and mesotheliomas with clear cytoplasm containing large amounts of glycogen have been documented in the literature ${ }^{5,24}$ Another interesting finding was the presence of intracyto- 
plasmic lumina, which were observed in the small cell areas in two of the cases. In my experience, intracytoplasmic lumina are not an unusual finding as they are often seen in most subtypes of epithelioid mesotheliomas; however, because they have not been reported in small cell lung carcinomas, their demonstration may have some diagnostic value. In those instances in which the distinction between a mesothelioma with small cell features and a small cell carcinoma is difficult, immunohistochemical studies can assist in establishing the differential diagnosis. As previously mentioned, small cell mesotheliomas, in general, maintain the immunoprofile commonly seen in the more conventional types of mesotheliomas. It should be kept in mind, however, that some of the so-called 'positive mesothelioma markers', specifically calretinin and WT1, which are commonly expressed in epithelioid mesotheliomas, have also occasionally been found to be positive in small cell lung carcinomas. The percentage of calretinin expression reported in small cell lung carcinoma has ranged from about 40 to $50 \%$ of the cases; ${ }^{25,26}$ whereas, the positivity for WT1 is much lower (5\%). ${ }^{27}$ As a result of the common expression of CEA, TTF-1, MOC-31, and neuroendocrine markers, such as synaptophysin, in small cell lung carcinomas, but not in mesotheliomas with small cell features, immunostaining for these markers, when used in conjunction with some of the positive mesothelioma markers, can assist in discriminating small cell mesotheliomas from small cell lung carcinomas.

Mesotheliomas with small cell features, especially those with cytoplasmic clearing, can potentially be confused with Ewings sarcoma/PNETs as these tumors can also arise in the chest wall and involve the pleura and may present clear cell morphology as a result of the accumulation of large amounts of intracytoplasmic glycogen.$^{28}$ That none of the small cell mesotheliomas in this study were found to express CD99, a marker that is almost invariably strongly expressed in Ewings sarcoma/PNETs, indicates that immunostaining for this marker, when used in conjunction with some positive mesothelioma markers, such as WT1, podoplanin and mesothelin, which are negative in Ewings sarcoma/ PNETs, ${ }^{29-33}$ can help in distinguishing between these two malignancies.

DSRCT is a neoplasm that, although it most commonly arises in the abdominal or pelvic peritoneum in children and young adults, ${ }^{34}$ has also been reported, although less frequently, in the pleura, ${ }^{35-37}$ as well as in older individuals. ${ }^{34}$ In addition to its characteristic pattern of 'small blue cells' embedded in a dense fibrous stroma, DSRCTs may also exhibit a wide range of other morphologic features and, therefore, may potentially be confused with mesotheliomas, particularly those exhibiting small cell morphology. ${ }^{34}$ In contrast to mesotheliomas, however, DSRCTs can express some markers, such as MOC-31, Ber-EP4, and TAG-72, which are almost invariably absent in mesotheliomas. ${ }^{38,39}$ Similar to mesotheliomas, although, DSRCTs are often positive for WT1 $1^{29,38,40,41}$ and mesothelin. ${ }^{32}$ A main feature of DSRCT is the common expression of desmin in a globoid-like staining pattern. ${ }^{38}$ Although all of the mesotheliomas with small cell features in the present series were desmin negative, desmin expression has been reported in a minority of epithelioid mesotheliomas (about $5-10 \%$ ), but the staining has been described as weak and did not show the globoid or dot-like pattern often seen in DSRCTs. ${ }^{42,43}$

Synovial sarcomas can originate in or metastasize to the pleura or chest wall and, like mesothelioma, may present a wide variety of morphologic appearances, including the small cell variant of poorly differentiated synovial sarcoma, which may resemble a mesothelioma with small cell features. ${ }^{44-46}$ Additionally, these tumors may also express some of the mesothelioma markers, including calretinin, mesothelin, and podoplanin..$^{18,47}$ However, synovial sarcomas do not exhibit WT1 positivity, a marker that is frequently expressed in mesotheliomas, including those with small cell features; therefore, immunostaining for WT1 may assist in the differential diagnosis between these malignancies. ${ }^{47}$ Another marker that can be useful in this differential diagnosis is bcl-2, which has been reported to be expressed in 79 to $100 \%$ of synovial sarcomas, but in only 0 to $10 \%$ of mesotheliomas. ${ }^{48-51}$ It should be mentioned, however, that TLE1, a marker that has an important role in the Wnt pathway and that has been shown to be a highly sensitive and specific immunohistochemical marker for synovial sarcoma, ${ }^{52}$ was found in a recent study to be variably expressed in about $70 \%$ of mesotheliomas regardless of their histomorphologic subtype, thus demonstrating that immunostaining for this marker has little or no value in discriminating between synovial sarcomas and mesotheliomas. ${ }^{53}$ Additionally, the demonstration of the distinctive $t(x ; 18)(p 11 ; q 11)$ translocation that is reportedly present in nearly all synovial sarcomas can help to establish the correct diagnosis. ${ }^{54,55}$

In conclusion, while mesotheliomas with small cell features are rare, pathologists should be aware of their existence as they can potentially be confused with a variety of other tumors that may also present small cell morphology. In summary, small cell mesotheliomas are characterized, histologically, by being composed of small cells usually growing in solid nests of closely packed cells, with well-defined cell borders and a high nuclear cytoplasmic ratio. The nuclei have finely granular and dispersed chromatin, often contain a small nucleolus, and exhibit no nuclear molding. Apoptotic bodies are usually absent and mitotic activity can be present, but it is much lower than in small cell lung carcinomas. The cytoplasm is eosinophilic, but can sometimes be clear because of the accumulation of large amounts of glycogen. The immunohisto- 
chemical profile is similar to that seen in other subtypes of epithelioid mesothelioma. Immunohistochemical studies can have an important role in establishing the differential diagnosis of a small cell mesothelioma in those instances where it is difficult to do so on routine histology.

\section{Disclosure/conflict of interest}

The author declares no conflict of interest.

\section{References}

1 Nascimento AG, Keeney GL, Fletcher CD. Deciduoid peritoneal mesothelioma. An unusual phenotype affecting young females. Am J Surg Pathol 1994;18:439-445.

2 Ordóñez NG. Epithelial mesothelioma with deciduoid features: report of four cases. Am J Surg Pathol 2000; 24:816-823.

3 Shia J, Erlandson RA, Klimstra DS. Deciduoid mesothelioma: a report of 5 cases and literature review. Ultrastruct Pathol 2002;26:355-363.

4 Ordóñez NG, Myhre M, Mackay B. Clear cell mesothelioma. Ultrastruct Pathol 1996;20:331-336.

5 Ordóñez NG. Mesothelioma with clear cell features: an ultrastructural and immunohistochemical study of 20 cases. Hum Pathol 2005;36:465-473.

6 Cook DS, Attanoos RL, Jalloh SS, et al. 'Mucin-positive' epithelial mesothelioma of the peritoneum: an unusual diagnostic pitfall. Histopathology 2000;37:33-36.

7 Allen TC. Recognition of histopathologic patterns of diffuse malignant mesothelioma in differential diagnosis of pleural biopsies. Arch Pathol Lab Med 2005;129:1415-1420.

8 Ordóñez NG. Mesothelioma with rhabdoid features: an ultrastructural and immunohistochemical study of 10 cases. Mod Pathol 2006;19:373-383.

9 Itami H, Ohbayashi C, Sakai Y, et al. Pleural malignant mesothelioma with osteoclast-like giant cells. Pathol Int 2010;60:217-221.

10 Kadota K, Suzuki K, Sima CS, et al. Pleomorphic epithelioid diffuse malignant pleural mesothelioma: a clinicopathological review and conceptual proposal to reclassify as biphasic or sarcomatoid mesothelioma. J Thorac Oncol 2011;6:896-904.

11 Ordóñez NG. Mesotheliomas with crystalloid structures: report of nine cases, including one with oncocytoid features. Modern Pathol; published online 28 October 2011 (e-pub ahead of print).

12 Martínez-Consuegra N, Muñoz-Juárez M, Ortiz-Hidalgo C. Unusual multifocal glomeruloid pattern in a well-differentiated papillary mesothelioma of the peritoneum. Int J Surg Pathol 2008;16:426-427.

13 Mayall FG, Gibbs AR. The histology and immunohistochemistry of small cell mesothelioma. Histopathology 1992;20:47-51.

14 Krismann M, Müller KM, Jaworska M, et al. Pathological anatomy and molecular pathology. Lung Cancer 2004;45(Suppl 1):S29-S33.

15 Hammar SP, Henderson DW, Klebe S, et al. Neoplasms of the pleura. In: Tomashefski JF, Cagle PT, Farver CF, Fraire AE (eds). Dail and Hammar's Pulmonary Pathology, Vol. II Neoplastic Lung Diseases 3rd edn. Springer Science+Business Media: New York, NY 2008, pp 558-734.
16 Churg A, Roggli V, Galateau-Salle F, et al. Mesothelioma. In: Travis WD, Brambilla E, Müller-Hermelink HK, Harris CC (eds). World Health Organization Classification of Tumours. Pathology \& Genetics. Tumours of the Lung, Pleura, Thymus and Heart. IARC Press: Lyon, France, 2004, pp 128-140.

17 Ordóñez NG. Value of mesothelin immunostaining in the diagnosis of mesothelioma. Mod Pathol 2003;16: 192-197.

18 Ordóñez NG. D2-40 and podoplanin are highly specific and sensitive immunohistochemical markers of epithelioid malignant mesothelioma. Hum Pathol 2005;36: 372-380.

19 Falconieri G, Zanconati F, Bussani R, et al. Small cell carcinoma of lung simulating pleural mesothelioma. Report of 4 cases with autopsy confirmation. Pathol Res Pract 1995;191:1147-1152.

20 Maeda Y, Segawa Y, Takigawa N, et al. Two cases of small cell lung cancer presenting an unusual pattern of progression mimicking pleural mesothelioma. Int $\mathrm{J}$ Clin Oncol 1998;3:121-124.

21 Murakami Y, Kanazawa K, Okuno K, et al. High-grade neuroendocrine carcinoma of the lung presenting an unusual spread mimicking pleural mesothelioma associated with dermatomyositis. Am J Med Sci 2004; 327:227-230.

22 Attanoos RL, Thomas DH, Gibbs AR. Synchronous diffuse malignant mesothelioma and carcinomas in asbestos-exposed individuals. Histopathology 2003;43: 387-392.

23 Cook HC. Small cell mesothelioma. Histopathology 1993;22:294-295.

24 Ordóñez NG, Mackay B. Glycogen-rich mesothelioma. Ultrastruct Pathol 1999;23:401-406.

25 Lugli A, Forster Y, Haas P, et al. Calretinin expression in human normal and neoplastic tissues: a tissue microarray analysis on 5233 tissue samples. Hum Pathol 2003;34:994-1000.

26 Miettinen M, Sarlomo-Rikala M. Expression of calretinin, thrombomodulin, keratin 5 , and mesothelin in lung carcinomas of different types: an immunohistochemical analysis of 596 tumors in comparison with epithelioid mesotheliomas of the pleura. Am J Surg Pathol 2003;27:150-158.

27 Carlson JW, Nucci MR, Brodsky J, et al. Biomarkerassisted diagnosis of ovarian, cervical and pulmonary small cell carcinomas: the role of TTF-1, WT-1 and HPV analysis. Histopathology 2007;51:305-312.

28 Llombart-Bosch A, Pellín A, Carda C, et al. Soft tissue Ewing sarcoma-peripheral primitive neuroectodermal tumor with atypical clear cell pattern shows a new type of EWS-FEV fusion transcript. Diagn Mol Pathol 2000;9:137-144.

29 Barnoud R, Sabourin JC, Pasquier D, et al. Immunohistochemical expression of WT1 by desmoplastic small round cell tumor: a comparative study with other small round cell tumors. Am J Surg Pathol 2000;24:830-836.

30 Carpentieri DF, Nichols K, Chou PM, et al. The expression of WT1 in the differentiation of rhabdomyosarcoma from other pediatric small round blue cell tumors. Mod Pathol 2002;15:1080-1086.

31 Jimenez RE, Folpe AL, Lapham RL, et al. Primary Ewing's sarcoma/primitive neuroectodermal tumor of the kidney: a clinicopathologic and immunohistochemical analysis of 11 cases. Am J Surg Pathol 2002;26:320-327. 
32 Ordóñez NG. Application of mesothelin immunostaining in tumor diagnosis. Am J Surg Pathol 2003;27: 1418-1428.

33 Ariizumi T, Ogose A, Kawashima H, et al. Expression of podoplanin in human bone and bone tumors: new marker of osteogenic and chondrogenic bone tumors. Pathol Int 2010;60:193-202.

34 Ordóñez NG. Desmoplastic small round cell tumor: I: a histopathologic study of 39 cases with emphasis on unusual histological patterns. Am J Surg Pathol 1998;22:1303-1313.

35 Choi JK, van Hoeven K, Brooks JJ, et al. Desmoplastic small round cell tumor presenting in pleural fluid and accompanied by desmin-positive mesothelial cells. Acta Cytol 1995;39:377-378.

36 Parkash V, Gerald WL, Parma A, et al. Desmoplastic small round cell tumor of the pleura. Am J Surg Pathol 1995;19:659-665.

37 Karavitakis EM, Moschovi M, Stefanaki K, et al. Desmoplastic small round cell tumor of the pleura. Pediatr Blood Cancer 2007;49:335-338.

38 Ordóñez NG. Desmoplastic small round cell tumor: II: an ultrastructural and immunohistochemical study with emphasis on new immunohistochemical markers. Am J Surg Pathol 1998;22:1314-1327.

39 Ordóñez NG. The immunohistochemical diagnosis of mesothelioma: a comparative study of epithelioid mesothelioma and lung adenocarcinoma. Am J Surg Pathol 2003;27:1031-1051.

40 Lae ME, Roche PC, Jin L, et al. Desmoplastic small round cell tumor: a clinicopathologic, immunohistochemical, and molecular study of 32 tumors. Am J Surg Pathol 2002;26:823-835.

41 Zhang PJ, Goldblum JR, Pawel BR, et al. Immunophenotype of desmoplastic small round cell tumors as detected in cases with EWS-WT1 gene fusion product. Mod Pathol 2003;16:229-235.

42 Salman WD, Eyden B, Shelton D, et al. An EMA negative, desmin positive malignant mesothelioma: limitations of immunohistochemistry? J Clin Pathol 2009;62:651-652.

43 Tsukiji H, Takeshima Y, Amatya VJ, et al. Myogenic antigen expression is useful for differentiation between epithelioid mesothelioma and non-neoplastic mesothelial cells. Histopathology 2010;56:969-974.

44 Masui F, Matsuno Y, Yokoyama R, et al. Synovial sarcoma, histologically mimicking primitive neuro- ectodermal tumor/Ewing's sarcoma at distant sites. Jpn J Clin Oncol 1999;29:438-441.

45 de Silva MV, McMahon AD, Paterson L, et al. Identification of poorly differentiated synovial sarcoma: a comparison of clinicopathological and cytogenetic features with those of typical synovial sarcoma. Histopathology 2003;43:220-230.

46 Kwon MS. Aspiration cytology of pulmonary small cell variant of poorly differentiated synovial sarcoma metastatic from the tongue: a case report. Acta Cytol 2005;49:92-96.

47 Miettinen M, Limon J, Niezabitowski A, et al. Calretinin and other mesothelioma markers in synovial sarcoma: analysis of antigenic similarities and differences with malignant mesothelioma. Am J Surg Pathol 2001;25:610-617.

48 Chilosi M, Facchettti F, Dei Tos AP, et al. bcl-2 expression in pleural and extrapleural solitary fibrous tumours. J Pathol 1997;181:362-367.

49 Suster S, Fisher C, Moran CA. Expression of bcl-2 oncoprotein in benign and malignant spindle cell tumors of soft tissue, skin, serosal surfaces, and gastrointestinal tract. Am J Surg Pathol 1998;22:863-872.

50 Cappello F, Barnes L. Synovial sarcoma and malignant mesothelioma of the pleura: review, differential diagnosis and possible role of apoptosis. Pathology 2001; 33:142-148.

51 Attanoos RL, Griffin A, Gibbs AR. The use of immunohistochemistry in distinguishing reactive from neoplastic mesothelium. A novel use for desmin and comparative evaluation with epithelial membrane antigen, p53, platelet-derived growth factor-receptor, P-glycoprotein and Bcl-2. Histopathology 2003;43:231-238.

52 Terry J, Saito T, Subramanian S, et al. TLE1 as a diagnostic immunohistochemical marker for synovial sarcoma emerging from gene expression profiling studies. Am J Surg Pathol 2007;31:240-246.

53 Matsuyama A, Hisaoka M, Iwasaki M, et al. TLE1 expression in malignant mesothelioma. Virchows Arch 2010;457:577-583.

54 Smith S, Reeves BR, Wong L, et al. A consistent chromosome translocation in synovial sarcoma. Cancer Genet Cytogenet 1987;26:179-180.

55 Limon J, Mrozek K, Mandahl N, et al. Cytogenetics of synovial sarcoma: presentation of ten new cases and review of the literature. Genes Chromosomes Cancer 1991;3:338-345. 